\title{
Association of Serum Cystatin C with Pre-eclampsia: A Case Control Study
}

\author{
NASIMAAKHTER ${ }^{1}$, FARZANA DEEBA ${ }^{2}$, BEGUM NASRIN ${ }^{3}$, SALEHABEGUM CHOWDHURY ${ }^{4}$
}

\begin{abstract}
s :
Background: Cystatin C, an endogenous marker of renal function, which increases in pregnancy as more so in pre-eclampsia, studies show it may be marker of pre-eclampsia.

Objective (s): The objective of the present work was to investigate the association between serum cystatin C levels in normal and pre-eclamptic pregnancy.

Methods and material: This case control study was conducted in the department of obstetrics and gynaecology in three tertiary care hospitals of Dhaka city (BSMMU, DMC, BIRDEM) during the period from January 2009 to December 2010. A total 240 women of 20-40 wks of pregnancy were enrolled in the study. One hundred and twenty four women of pre-eclampsia were recruited as case and 116 healthy pregnant women were enrolled as control. Serum cystatin $C$ was measured in both case and control by a fully automated particle-enhanced immune-turbidimetric assay for cystatin $C$ in undiluted samples. Serum cystatin $C$ level was compared between the groups. $P$ value reached from unpaired student $t$-test and chi square test by analyzing the data. $P$ value less than 0.05 was considered to be significant.

Results: The mean $( \pm S D)$ serum cystatin $C$ levels in case group was $1.17 \pm 0.34 \mathrm{mg} / \mathrm{lranged}$ from 0.1-2.2 mg/l. In control groups the mean ( $\pm S D$ ) serum cystatin C level was $0.87 \pm 0.31$ $\mathrm{mg} / \mathrm{l}$, ranged from 0.24-1.98 $\mathrm{mg} / \mathrm{l}$, which was significantly higher $(p<0.001)$ in case. There was statistically significant association between serum cystatin $C$ and pre-eclampsia. Serum Cystatin C level $>1 \mathrm{mg} / \mathrm{l}$ was found in more than half (69\%) of the cases compared to $25 \%$ of the control group $(p<0.001)$. Computation of odds ratio reveals that the cases had 6.79 times higher risk of having pre-eclampsia than that of the control group $(p<0.001)$.
\end{abstract}

Conclusion: There is significant association between pre-eclampsia and serum cystatin $C$.

\section{Introduction}

Pre-eclampsia, a hypertensive disorder in pregnancy, is one of the most important complication leading to maternal and perinatal morbidity and mortality ${ }^{1}$. It occurs in $5-8 \%$ of pregnancy worldwide ${ }^{2}$. In baseline EOC (emergency obstetric care) survey of Bangladesh, $5 \%$ of total obstetric admission is due pre-eclampsia and eclampsia in health care facilities ${ }^{3}$. It is the most serious hypertensive disease in pregnancy defined as hypertension with significant proteinuria ${ }^{4}$. The degree of proteinuria has traditionally been used to determine severity of disease ${ }^{5}$.

Deterioration of kidney function is a major concern in pre-eclampsia, Most characteristic morphological abnormality is glomerular endotheliosis, which might be a better indicator of the state of risk of pregnancy complications associated with pre-eclampsia than proteinuria has proved to $b^{6}{ }^{6}$. Glomerular endotheliosis, defined as swelling and vacuolisation of the endothelial cells in the renal glomeruli with obliteration of the endothelial fenestrae and an encroachment of the capillary space area, is the typical structural lesion of pre-eclampsia ${ }^{7}$.

Glomerular endotheliosis, involving a reduction in size and number of endothelial fenestrae, has been calculated to make an important contribution to impairment of hydraulic permeability of the capillary wall, causing glomerular filtration rate to be decreased. Asensitive glomerular filtration rate marker

1. Consultant of Obstetric and Gynaecology

2. Assistant Professor, Infertility Unit, Dept. of Obs \& Gynae, Bangabandhu Sheikh Mujib Medical University (BSMMU).

3. Professor, Dept. of Obs \& Gynae, Bangabandhu Sheikh Mujib Medical University (BSMMU).

4. Chairman, Dept. of Obs \& Gynae, Bangabandhu Sheikh Mujib Medical University (BSMMU).

Correspondence : Dr. Farzana Deeba, Assistant Professor, Department of Obstetrics \& Gynaecology, Bangabandhu Seikh Mujib Medical University, Dhaka, Bangladesh, Cell phone: +8801711535404, Email: deeba_51@yahoo.com 
could therefore be expected to reflect the degree of glomerular endotheliosis and possibly the degree of the pre-eclamptic state ${ }^{8}$.

Although high blood pressure and albuminuria must be regarded as the simplest and most useful markers of the development of pre-eclampsia, blood pressure levels are highly variable, especially in pre-eclampsia, and albuminuria can be absent, even with other serious features of pre-eclampsia ${ }^{9}$. A less variable marker reflecting endotheliosis would be valuable in clinical use.

Cystatin $\mathrm{C}$ is an endogenous marker of renal function because of its stable production rate from all nucleated cells and its almost exclusive elimination from the circulation by glomerular filtration ${ }^{9-10}$. Pregnancy increases plasma cystatin $\mathrm{C}$, but levels are much higher in preeclampsia and its serum concentration generally reflects the glomerular filtration ${ }^{11}$. It has also been shown to be a better marker for preeclampsia than serum creatinine or urate ${ }^{12}$.Previous studies have not quantified preeclampsia risk with varying cystatin $\mathrm{C}$ concentrations or adjusted for confounders ${ }^{11-12}$.

In recent studies, it was shown that serum cystatin $\mathrm{C}$ in pregnancy is closely associated to pre-eclampsia. The objective of the present work was to investigate the association between serum cystatin $C$ levels and in normal and pre-eclamptic pregnancy, and to evaluate the possible use of serum cystatin $C$ as a marker for the early prediction of pre-eclamptia. So aim of this study was to evaluate the association of serum cystatin C level with pre-eclampsia

Methods and material: The study was conducted in the department of obstetrics and gynaecology of three tertiary care hospital of Dhaka city (BSMMU, DMC, BIRDEM) during the period from January 2009 to December 2010. This was a case control study and purposive sampling was done. A total 240 women of $20-$ $40 \mathrm{wks}$ of pregnancy were enrolled in the study. 124 women of mild to severe pre-eclampsia were recruited as case and 116 healthy pregnant women with matched gestational age 20-40 wks were enrolled as control.

\section{Exclusion criteria:}

- pregnancy with chronic hypertension

- pregnancy with DM

- pregnancy with chronic renal disease

- pregnancy with connective tissue disease

- multiple gestation

- smoker

- Pregnancy with other medical disorder

Diagnostic criteria for Pre-eclampsia: Gestational hypertension was defined as diastolic blood pressure above $90 \mathrm{mmHg}$ determined on two or more consecutive occasions more than 4 hours apart and after 20 weeks of gestation. Pre-eclampsia was defined as gestational hypertension with urine albumin concentrations exceeding $300 \mathrm{mg} / \mathrm{L}$ in two random clean-catch-midstream specimens collected 4 hours or more apart ${ }^{1-2}$. All pregnancies had been dated according to routine ultrasonographic measurement of the fetal biparietal diameter and femur length in the 17-18th week of gestation.

Informed consent was obtained from all participating women. The ethics committee of the institutes approved the study and all procedures involving the participants were in accordance with the Helsinki Declaration of 1975.

Serum cystatin $C$ was measured in both case and controls by a fully automated particle-enhanced immunoturbidimetric assay for cystatin $\mathrm{C}$ in undiluted samples. The total analytical (intra-assay + interassay) imprecision of the method, calculated using a control sample in age, BMI and gestational age matched both groups were done.

Serum cystatin C level was compared between the groups. Statistical analysis was done by SPSS (version 12.0) statistical software. $P$ value reached from unpaired student t-test and chi square test by analyzing the data. $P$ value less than 0.05 was considered to be significant.

\section{Result}

A total 240 women of 20-40 wks of pregnancy were enrolled in the study; 124 women of pre-eclampsia were recruited as case and 116 healthy pregnant women were enrolled as control. Study showed, there was no significant difference in mean age, $\mathrm{BMI}$ and gestational age of the cases and in the controls. About $54 \%$ subject was primipara in case in contrast to $64.7 \%$ in controls (Table-I).

The mean $( \pm S D)$ serum cystatin levels in case group was $1.17 \pm 0.34 \mathrm{mg} / \mathrm{l}$ which ranged from $0.1-2.2 \mathrm{mg} / \mathrm{l}$. In control groups the mean $( \pm S D)$ serum cystatin level was $0.87 \pm 0.31 \mathrm{mg} / \mathrm{l}$ which ranged from 0.24 $1.98 \mathrm{mg} / \mathrm{l}$, which was significantly lower $(p<0.001)$ than case group. There was statistically significant association between serum cystatin $\mathrm{C}$ and preeclampsia. More than half $(69 \%)$ of the cases had high level of serum Cystatin $C(>1 \mathrm{mg} / \mathrm{l})$ compared to $25 \%$ of the control group ( $p<0.001)$ (Table-II) . Computation of odds ratio reveals that the cases (Table-III) had 6.79 times higher than that of the control group $(p<0.001)$. 
Table- I

Comparison of socio-demographic variables between groups $N=200$

\begin{tabular}{lccl}
\hline Variables & Case $(\mathrm{n}=124)$ & Control $(\mathrm{n}=116)$ & P value \\
\hline Mean Age $(\mathrm{yrs})$ & $25.6 \pm 4.37$ & $25.4 \pm 5.56$ & $0.756^{\mathrm{ns}}$ \\
Mean BMI $\left(\mathrm{kg} / \mathrm{m}^{3}\right)$ & $22.42 \pm 2.57$ & $21.93 \pm 1.59$ & $0.235^{\mathrm{ns}}$ \\
Mean Gestational age(wks) & $31.42 \pm 3.57$ & $31.93 \pm 4.59$ & $0.335^{\mathrm{ns}}$ \\
Primipara(\%) & 54.0 & 64.7 & $0.094^{\mathrm{ns}}$ \\
\hline
\end{tabular}

$\mathrm{s}=$ significant; $\mathrm{ns}=$ not significant

$P$ value was achieved by student $t$ test.

Table-II

Comparison the level of Serum cystatin between the groups $(n=240)$

\begin{tabular}{lccc}
\hline Serum Cystatin C & \multicolumn{2}{c}{ Group } & P Value \\
\hline & Case $(\mathrm{n}=100)$ & Control $(\mathrm{N}=100)$ & \\
Mean $\pm \mathrm{SD}(\mathrm{mg} / \mathrm{L})$ & $1.17 \pm 0.34$ & $0.87 \pm 0.31$ & $0.001^{\mathrm{s}}$ \\
Range $(\mathrm{mg} / \mathrm{L})$ & $(0.1-2.2)$ & $(0.24-1.98)$ & \\
\hline
\end{tabular}

$\mathrm{SD}=$ standard deviation

$P$ value was obtained by student $t$ test.

Table- III

Comparison of Serum cystatin level between the groups $(n=240)$

\begin{tabular}{lcccc}
\hline Cystatin C & \multicolumn{2}{c}{ Group } & P-Value & OR(95\% Cl) \\
\cline { 2 - 4 } & Case $\mathrm{n}=124(\%)$ & Control $\mathrm{n}=116(\%)$ & & \\
\hline $21 \mathrm{mg} / \mathrm{l}$ & $86(69.4)$ & $29(25.0)$ & $0.001^{\mathrm{s}}$ & 6.79 \\
$<1 \mathrm{mg} / \mathrm{l}$ & $38(30.6)$ & $87(75.0)$ & & \\
\hline
\end{tabular}

${ }^{*}$ Chi-square test was done to measure the level of significance.

\section{Discussion:}

This case control study was carried out in the department of obstetrics and gynaecology in three tertiary care hospital of Dhaka city with an aim to evaluate the association of serum cystatin c level with pre-eclampsia.

The mean age $( \pm S D)$ was $25.6 \pm 4.37$ and $25.4 \pm 5.56$ in case and controls respectively and there was no significant difference in mean age. Study by Franceschini et al, Kristensen, Larsson and Hansson showed significantly higher mean age in control groups $^{13-14}$. Geographical and socio-economic factors may have significance on the age of marriage.

No statistically significant difference was found in mean BMI and gestational age between the cases and in the controls which was similar to the study done by Kristensen et al and Thilaganathan et al ${ }^{14-}$ 15 . Fifty four percent was primipara in case in contrast to $64.7 \%$ in controls which closely resembles to the study of Franceschini et $\mathrm{al}^{13}$.

In the current study the mean $( \pm S D)$ serum cystatin levels in case was $1.17 \pm 0.34 \mathrm{mg} / \mathrm{l}$ which ranged from 0.1-2.2 mg/l. In control groups the mean $( \pm S D)$ serum cystatin level was $0.87 \pm 0.31 \mathrm{mg} / \mathrm{l}$ which ranged from $0.24-1.98 \mathrm{mg} / \mathrm{l}$. The level was significantly higher $(p<0.001)$ in case group which is comparable to the study done by Franceschini et al and Kristensen and Larsson and Hansson ${ }^{14}$.

More than half $(69 \%)$ of the cases had level of serum Cystatin C (>1mg/l) compared to $25 \%$ of the control group $(p<0.001)$. Computation of odds ratio reveals that the cases had 6.79 times higher risk of having 
pre-eclampsia than that of the control group $(p<0.001)$ which closely resembled with the risk estimated by Franceschini et al. The author compared the estimated risk was approximately 6 -fold with first quartile, 8-fold in second quartile, 3.6-fold for third quartile and 12- fold for forth quartile ${ }^{13}$.

In the present study association between preeclampsia and serum cystatin C, found to be highly significant. The current work suggested that serum cystatin $C$ might be act as a marker for early prediction of pre-eclamsia and it might be of value in monitoring the renal features of pre-eclampsia,

\section{Conclusion}

There is significant association between preeclampsia and serum cystatin $C$ and the pregnant patients with high serum cystatin $C$ level have more than six fold increase risk of developing pre-eclampsia than healthy pregnancy.

\section{References}

1. Gibson,J.M,Swerdlow,A.J, Head,J.A, Marmot,M., Maternal mortality in England and Wales 1970-1985: an analysis by country of birth. Br J Obstet Gynecol 1996;103: 973-980.

2. Duley,L., Maternal mortality associated with hypertensive disorder of pregnancy in Africa, Asia, Latin America and Carabia: Br J Obstet Gynecol 1992;99:547-553.

3. Yasmin H.A, Rahman, M.H, Chowdhury F.K, Baseline survey for emergency obstetric care service in Bangladesh.Banglades institute of Research for promotion of essential and reproductive health and technology.1995:10

4. Report of the National High Blood Pressure Education Program Working Group on high blood pressure in pregnancy. Am J Obstet Gynecol 2000;183:1-22.

5. National high blood pressure education program working group: report on high blood pressure in pregnancy. Am J Obstet Gynecol 1990;163: 1689-1712.

6. Higgins JR, de Swiet M. Blood pressure measurement and classification in pregnancy. Lancet 2001;357: 131-135.

7. Spargo $\mathrm{BH}, \mathrm{McC}$ artney $\mathrm{C}$, Winemiller R. Glomerular capillary endotheliosis in toxemia of pregnancy. Arch Pathol 1959;13: 593-599.

8. Lafayette RA, Druzin M, Sibley R, et al. Nature of glomerular dysfunction in pre-eclampsia. Kidney Int 1998;54: 1240-1249.

9. Simonsen O, Grubb A, Thysell H. The blood serum concentration of cystatin $\mathrm{C}\left({ }^{3}\right.$-trace) as a measure of the glomerular filtration rate. Scand J Clin Lab Invest 1985;45: 97-101.

10. Grubb AO. Cystatin C - properties and use as a diagnostic marker. Adv Clin Chem 2000;35: 6399.

11. Strevens $H$, Wide-Swensson D, Torffvit $O$, Grubb A. Serum cystatin C for assessment of glomerular filtration rate in pregnant and nonpregnant women. Indications of altered filtration process in pregnancy. Scand J Clin Lab Invest 2001;62(2):141-147.

12. Strevens $H$, Wide-Swensson D, Grubb A. Serum cystatin $\mathrm{C}$ is a better marker for preeclampsia than serum creatinine or serum urate. Scand $\mathrm{J}$ Clin Lab Invest 2001;61: 575-580.

13. Franchini N, Qua C, Barrow DA, Williams MA, Cystatin $C$ and Preeclampsia: a case control study: Ren Fail. 2008; 30(1):89-95

14. Karl Kristensen1, I. Larsson ,S.R. Hansson .Increased cystatin C expression in the preeclamptic placenta: Moleculer human reproduction,13(3),189-195

15. Thilaganathan B, Ralph ET,Papageorghiou, A, Melchiorre K, Sheldon, J,Raised Maternal Serum Cystatin C: An Early Pregnancy Marker for Preeclampsia, 2009,16:788-793. 